\title{
Structural and metabolic disturbances in brain histaminergic neurons following alcohol administration in rats
}

\author{
Katsiaryna M Phedina and Sergey M Zimatkin \\ Grodno State Medical University, Grodno, Belarus
}

\begin{abstract}
Aim: The aim of the study was to analyze the structural and metabolic disturbances in the brain histaminergic neurons in conditions of acute and subacute alcohol intoxications.

Methods: Experiments were performed on 77 male Wistar rats weighing $175 \pm 23 \mathrm{~g}$. Rats of the $1^{\text {st }}$ group were decapitated at $1 \mathrm{~h}$ after administration of the single dose of ethanol $\left(4 \mathrm{~g} / \mathrm{kg}\right.$ as $20 \%$ saline solution $(0.85 \mathrm{NaCl})$, i.p.). The rats of the $2^{\text {nd }}$ group were decapitated at $1 \mathrm{~h}$ after the last administration of $20 \%$ ethanol solution in saline at a dose of $4 \mathrm{~g} / \mathrm{kg} / \mathrm{day}$, i.p., for 7 days. Control animals were injected by the same volume of saline. Histaminergic neurons of the hypothalamus nucleus $\mathrm{E} 2$ were examined by the histological, histochemical, electron microscopic and morphometric methods.

Results: Acute and subacute alcohol administrations cause disturbances of the cytoplasm chromatophilia of brain histaminergic neurons, lead to rounding of their perikarya and nuclei. Under the influence of subacute alcohol intoxication, the histaminergic neurons bodies become larger. Following single and seven-day ethanol administrations the metabolic activity of those neurons decreases. It is accompanied by acceleration of processes of the brain histamine oxidative deamination, activation of anaerobic glycolysis and intensification of autophagy processes. Single administration of alcohol leads to the development of destructive and adaptive ultrastructural changes in histaminergic neurons (activation of the nuclear apparatus, disturbance of the organization of mitochondria, endoplasmic reticulum and Golgi apparatus, lysosomal hyperplasia). Subacute alcohol administration induces more severe ultrastructural disorders.

Conclusion: Acute and subacute alcohol intoxications lead to morphological and functional disorders of brain histaminergic neurons, adaptive structural and metabolic changes of those neurons, some being common to single and repeated administration regimes and others being dependent on duration of exposure to alcohol.
\end{abstract}

\section{Introduction}

The histaminergic system is one of the neurotransmitter systems of the brain and its histaminergic neurons use histamine as a transmitter [1]. Brain histaminergic neurons are located exclusively in the posterior hypothalamus from where they send projections to almost all regions of the central nervous system, regulating other transmitter systems [2,3]. These neurons are grouped into five clusters (nuclei) denominated E1E5 [4,5], among which E2 nucleus is the largest, and where more than half of these neurons is concentrated [6] (Figure 1).

The brain histaminergic system modulates a variety of physiological functions and processes such as wakefulness, sleep-wake cycle, feeding and drinking behavior, learning and memory, stress, seizure, and emotion [1,3,5,7-10]. It participates in regulation of alcohol consumption, alcohol-induced behaviors and alcoholism pathogenesis [10-13]. At the same time alcohol has significant influence on the histamine content and metabolism in the brain and causes various morphological and histochemical disorders of brain histaminergic neurons [13].

The aim of the present study was to analyze and compare the histological, histochemical and ultrastructural changes in histaminergic neurons of the E2 hypothalamic nucleus in conditions of acute and subacute exposures to alcohol.

\section{Materials and methods}

\section{Animals, experimental design and chemicals}

77 male Wistar rats were obtained from the breeding colony of the Grodno State Medical University. Their weight was $175 \pm 23 \mathrm{~g}$. All experimental procedures complied with European Community Council Directive (86/609/EEC) for care and use of laboratory animals. Protocols were reviewed and approved by the Ethical Committee of the Grodno State Medical University. Rats were housed 6-7 per cage $(40$ x $60 \mathrm{~cm})$ with free access to food and water and kept under controlled environmental conditions. All efforts were made to minimize animal suffering.

Acute exposure to alcohol: $20 \%$ ethanol solution in saline $(0.85 \%$ $\mathrm{NaCl}$ ) was injected to rats at a dose of $4 \mathrm{~g} / \mathrm{kg}$, i.p., from 9 till 11 a.m.

Correspondence to: Sergey M. Zimatkin, Department of Histology, Cytology and Embryology, Grodno State Medical University, 80 Gorkogo street, Grodno, 230015, Belarus; Tel: (375)(152)742492; E-mail: smzimatkin@mail.ru

Key words: alcohol, brain, histaminergic neurons, structure, cytochemistry

Received: November 20, 2017; Accepted: December 16, 2017; Published: October 19, 2017 

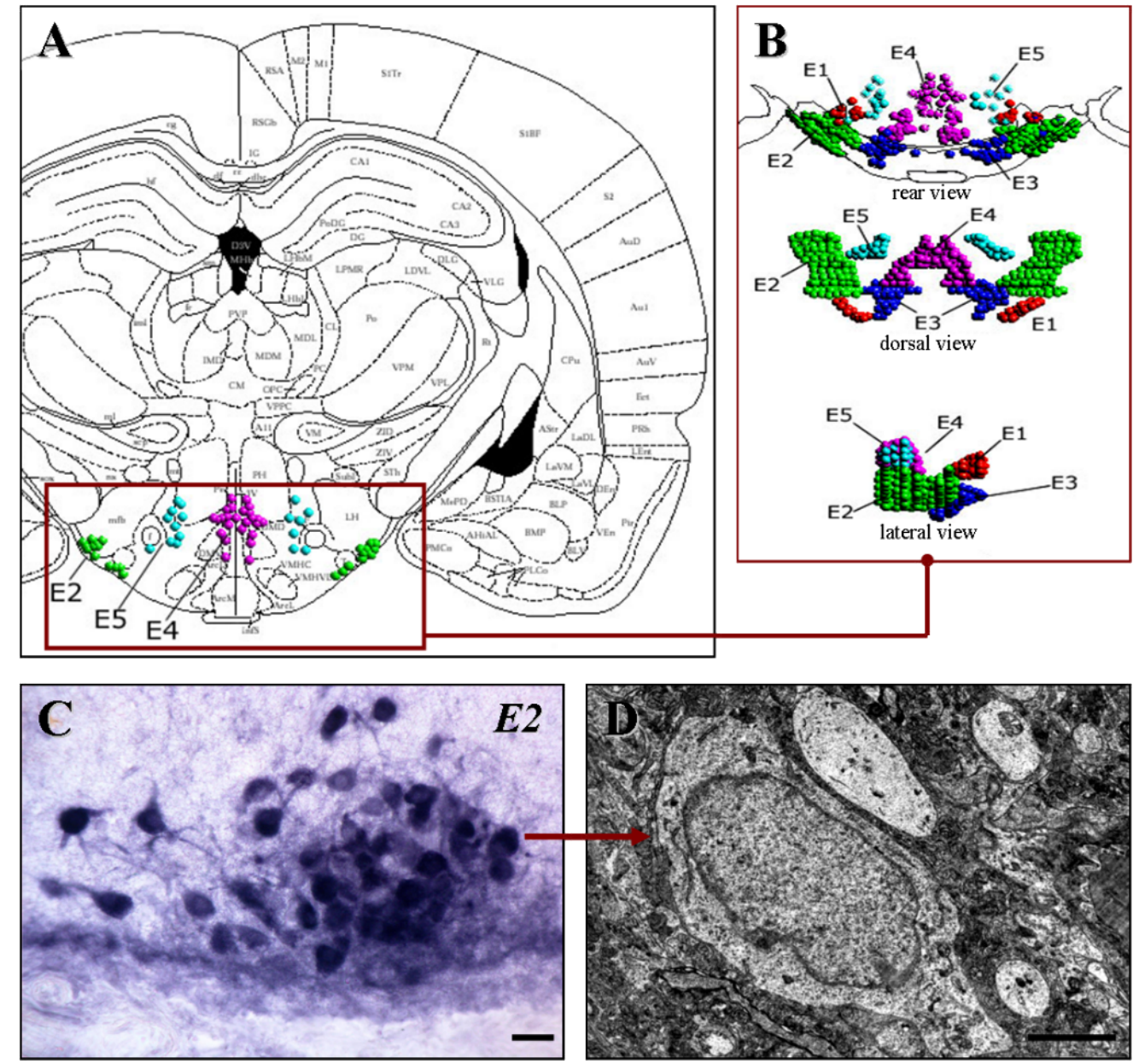

Figure 1. Location of E2 histaminergic neurons in rat hypothalamus

A-Histaminergic neurons nuclei on the scheme from a stereotaxic atlas [7].

B-Three-dimensional images of histaminergic neurons nuclei [6].

C-Histochemical staining of histaminergic neurons for monoamine oxidase type B, the marker enzyme of histaminergic neurons. Digital microphotography. Magnification: $\mathrm{x} 200$. Scale bar: $15 \mu \mathrm{m}$. D-A histaminergic neuron in the electron micrograph. Scale bar: $2 \mu \mathrm{m}$

Control animals were injected by saline in the same volume parallel to ethanol-injected rats. All rats were decapitated $1 \mathrm{~h}$ after the injection.

Subacute exposure to alcohol: $20 \%$ ethanol solution in saline $(0.85 \% \mathrm{NaCl})$ was injected to rats of test group at a dose of $4 \mathrm{~g} / \mathrm{kg}$, i.p., daily, from 9 till 11 a.m. during 7 days. Control animals were injected by saline in the same volume parallel to ethanol-injected rats. All rats were decapitated $1 \mathrm{~h}$ following the last injection.

\section{Histology and histochemistry}

Rats were anesthetized and fresh brain was removed following decapitation. Pieces of hypothalamus were then obtained, frozen and stored in liquid nitrogen for further analysis. When the brain structures were identifying, a stereotaxic atlas was using [7]. 10- $\mu \mathrm{m}$ serial frontal sections of the frozen hypothalamus were prepared using a cryostat (Leica CM 1840, Germany). They were stained with a $0.1 \%$ solution of toluidine blue (Nissl method) to assess general cytology of neurons. The activity of the marker enzyme of histaminergic neurons, monoamine oxidase type B (MAO B, EC1.4.3.4) was detected using the method published by us earlier [14]. To assess the activity of the oxidizing enzymes, such as succinate dehydrogenase (SDH, EC 1.3.99.1), lactate dehydrogenase (LDH, EC 1.1.1.27), glucose-6-phosphate dehydrogenase (G-6-PhDH, EC 1.1.1.49),
NADH dehydrogenase (NADHDH, EC, 1.1.1.49) and NADPhH dehydrogenase (NADPhHDH, EC, 1.6.1.1), as well as to estimate the activity of marker lysosomal enzyme acid phosphatase (AP, EC 1.4.3.4), we used histochemical methods [15]. For the enzyme histochemistry the cryostat sections were placed into the corresponding incubation medium, including the buffer, substrate, co-factor, if necessary, and chromogen, for 30 min-5 hours to visualize the location of enzymatic activity, then washed and embedded in the suitable plastic medium.

For the identification of histaminergic neurons in brain sections the stereotaxic atlas, corresponding topographic schemes and preparations stained for MAO B were used [6,7].

All the chemicals were obtained from Sigma-Aldrich (USA).

\section{Microphotography and morphometric analysis of histaminergic neurons}

The hypothalamus sections for histology and histochemistry were made in parallel (as serial-sections ribbon). The location of E2 histaminergic neurons in preparations stained by Nissl method was compared with preparations stained for MAO B. The examination of histological preparations, their microphotography and morphometry were perfomed using an Axioskop 2 Plus microscope (Zeiss, Germany), 
equipped with a digital video camera (Leica DFC 320, Germany) and computer image analysis software Image Warp (Bit Flow, USA). All visible histaminergic neurons were estimated according to their type of chromatophilia (the intensity of staining of neurons cytoplasm) and divided into normochromic (normal, medium staining), hyperchromic (intense staining), hypochromic (pale staining) and cell-shadows (very pale remnants of died neurons with no visible nucleus).

To estimate the size and shape of neuronal bodies and nuclei in preparations stained by Nissl method the images of up to 30 histaminergic neurons bodies and their nuclei were outlined in every preparation on the computer monitor and the mean values were used for the further statistics. Maximal and minimal diameter (D), perimeter $(\mathrm{P})$, area $(\mathrm{A})$ and volume, as well as form-factor $\left(4 \pi \mathrm{A} / \mathrm{P}^{2-}\right.$ parameter of sphericity and folding) and factor of elongation (maximal D/ minimal D-parameter of sphericity) were quantified in Nissl stained neurons bodies (perikarya).

The enzyme activities were determined in cytoplasm of neurons on the optic density of chromogen obtained in the course of histochemical reactions.

\section{Electron microscopy}

For electron microscopy the samples of the posterior hypothalamus were fixed in 2.5\% glutaraldehyde in Millonig buffer ( $\mathrm{pH} 7.4)$ for $4 \mathrm{~h}$ at $4^{\circ} \mathrm{C}$. Then the lateral parts of the posterior hypothalamus, where the histaminergic neurons of the largest group, E2, are situated, were fixed in $1 \%$ osmium tetroxide in Millonig buffer $(\mathrm{pH} \mathrm{7.4)}$ for $1 \mathrm{~h}$ at room temperature [16], dehydrated in an increasing concentration of ethanol and acetone and embedded in epoxide gum. The sections were obtained with an ultramicrotome MT-7000 (RMC, USA), contrasted by uranyl acetate [17] and lead citrate [18], and examined with a transmission electron microscope JEM-1011 (JEOL, Japan). Electron micrographs were acquired by a digital camera (Olympus MegaView III, Germany).

\section{Statistics}

The primary data obtained were processed with nonparametric statistics (because of the small number of animals in the groups) using software STATISTICA 6.0 (StatSoft, Inc., USA). In descriptive statistics, the values of median (Me) and interquartile range (IQR) were determined. The differences were considered significant at $\mathrm{p}<0.05$ (Mann-Whitney U-test).

\section{Results and discussion}

\section{Histological changes in histaminergic neurons following alcohol administration}

Acute and subacute alcohol intoxications cause disturbances of the cytoplasm chromatophilia. Thus, single administration of ethanol leads to an increase in the amount of cells-shadows and does not cause changes in the number of hypochromic and hyperchromic neurons (Figure 2). Seven-day ethanol administration causes a sharp increase in the number of cells-shadows and hypochromic neurons, that indicates the toxic effect of ethanol to histaminergic neurons.

Acute and subacute intoxications of ethanol lead to rounding of histaminergic neurons perikarya. Nuclei of those cells also become more roundish and spherical. Thus, $1 \mathrm{~h}$ after single ethanol administration form factor of histaminergic neurons perikarya and nuclei increases by $6.8 \%$ and $6.6 \%$, respectively, as compared to controls. Following multiple-dose introduction of alcohol ( $1 \mathrm{~h}$ after the last injection) form factor of histaminergic neuron perikarya and nuclei increases by $6.6 \%$ and $5.5 \%$, respectively (Figure 3 ).

Under the influence of single ethanol dose, the average sizes of histaminergic neurons do not significantly change. Nuclei of such cells

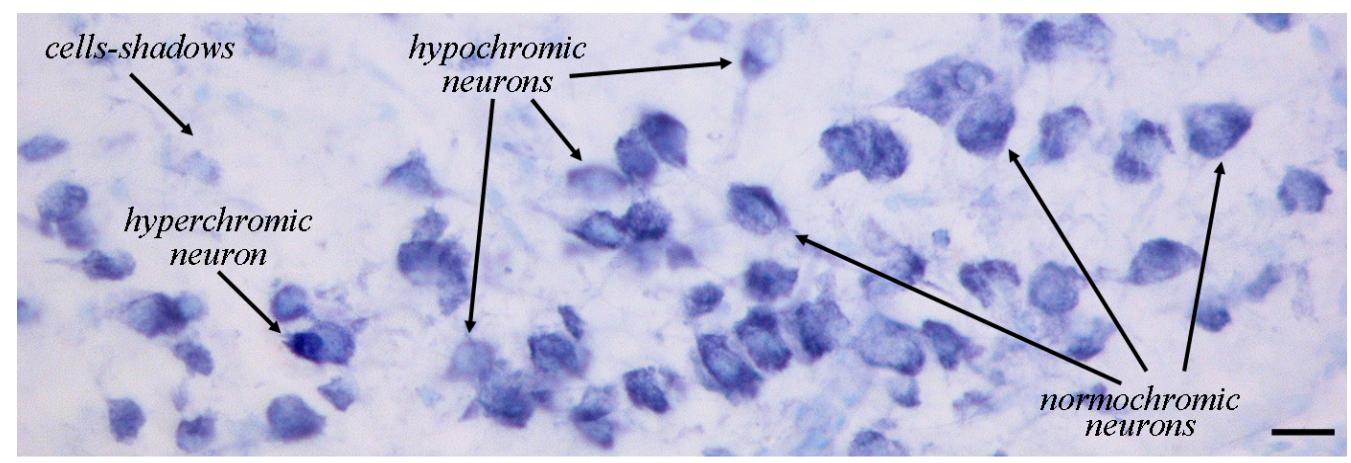

Types of chromatophilia of histaminergic neurons. Staining by the Nissl method. Digital microphotography. Magnification: x400. Scale bar: $15 \mu \mathrm{m}$
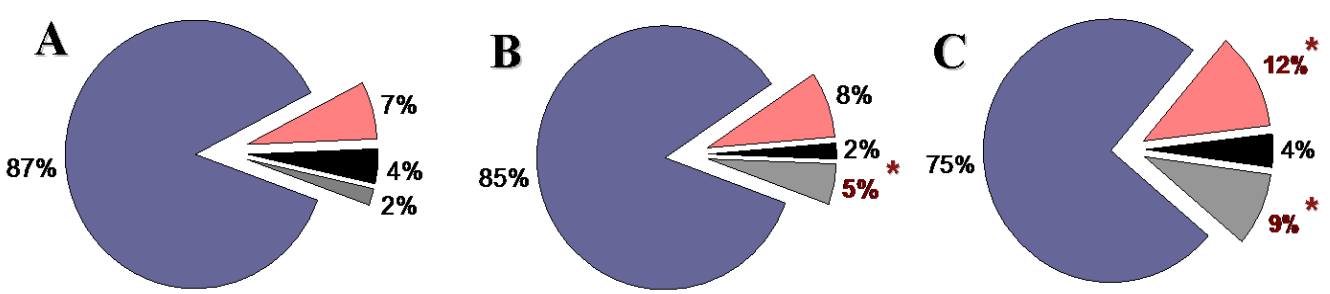

- normochromic neurons

- hypochromic neurons

- hyperchromic neurons

- cells-shadows

* $-\mathrm{p}<0,05$, as compared to controls (Mann-Whitney U-test)

Figure 2. Types of chromatophilia of histaminergic neurons of control rats (A), single ethanol administration at a dose of $4 \mathrm{~g} / \mathrm{kg}, 1 \mathrm{~h}$ after the injection (B), sevenfold ethanol administration at a dose of $4 \mathrm{~g} / \mathrm{kg} /$ day, $1 \mathrm{~h}$ after the last injection (C) 
Area of histaminergic neuron perikarya

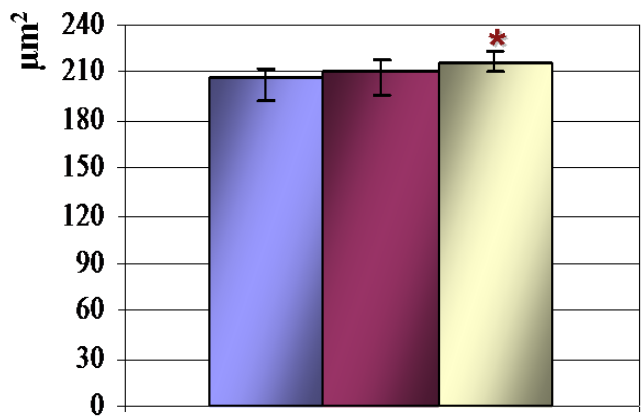

Area of histaminergic neuron nuclei

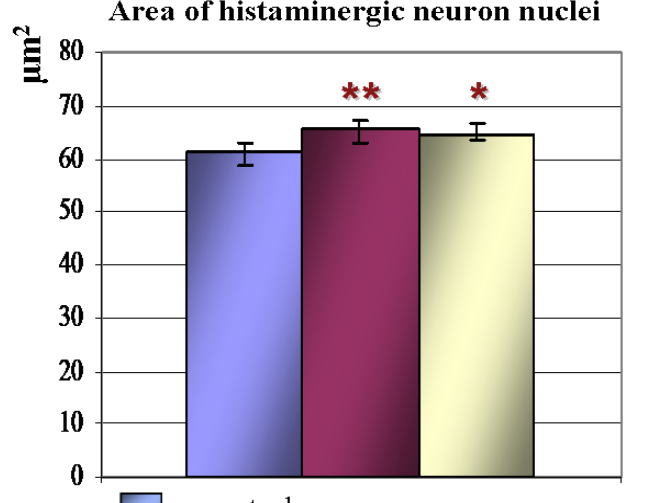

Form factor of histaminergic neuron perikarya

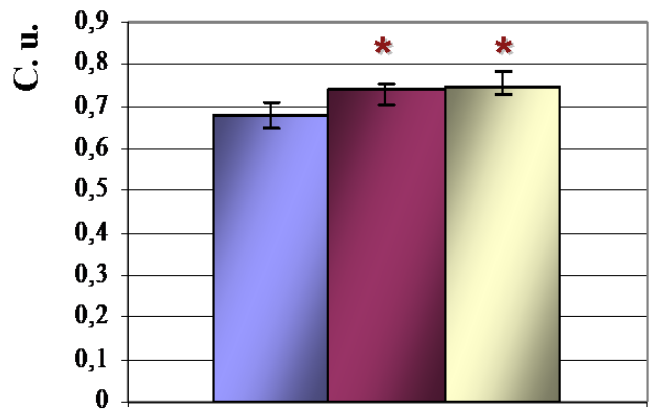

Form factor of histaminergic neuron nuclei

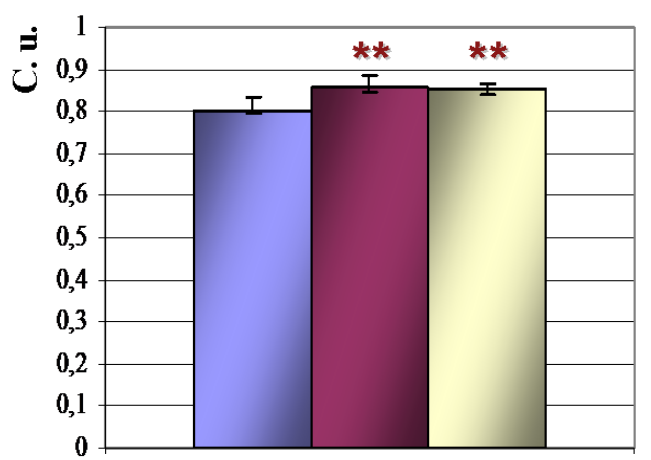

$\square$ - single ethanol administration at a dose of $4 \mathrm{~g} / \mathrm{kg}, 1 \mathrm{~h}$ after the injection

- sevenfold ethanol administration at a dose of $4 \mathrm{~g} / \mathrm{kg} / \mathrm{day}, 1 \mathrm{~h}$ after the last injection

Figure 3. Morphometric parameters of histaminergic neurons perikarya and nuclei in hypothalamus of control rats, following ethanol administration. Data are presented as Me \pm IQR; *-p $<0.05, *_{-}$p $<0.01$, as compared to controls

become larger: their average area increased by $6.5 \%$. Following sevenday ethanol administration the histaminergic neurons bodies and nuclei become larger: their average area increased by $4.5 \%$ and $5.3 \%$, respectively, as compared to controls (Figure 3 ). The observed increase in sphericity and rounding of histaminergic neurons perikarya and nuclei may be associated with a disturbance of the electrolyte balance or an alteration of the cytoskeleton of neurons, induced by ethanol.

\section{Histochemical changes in histaminergic neurons following alcohol administration}

Under the influence of alcohol there is a significant reorganization of the metabolism in brain histaminergic neurons. In an hour after single intraperitoneal administration of $20 \%$ ethanol solution at a dose of $4 \mathrm{~g} /$ $\mathrm{kg}$ the activity of MAO B (Figure 4A, 4B and 5), LDH (Figure 5) and AP (Figure 4D, 4E and 5) in histaminergic neurons perikarya increases by $17.1 \%, 12.3 \%$ and $25.1 \%$, respectively, that testifies activation of the processes of the brain histamine oxidative deamination, additional activation of late stages of the glycolysis proceeding in anaerobic conditions, and intensifying of autophagy processes.

The decrease of G-6-PhDH (by 22.9\%) (Figure 4G, $4 \mathrm{H}$ and 5) and NADPhHDH (by 17.6\%) activity is evidence of weakening extramitochondrial energy processes. Seven-day ethanol administration at a dose of $4 \mathrm{~g} / \mathrm{kg} /$ day leads to similar changes. The MAO B activity in the cytoplasm of histaminergic neurons increases by $8.8 \%$ (Figure $4 \mathrm{~A}, 4 \mathrm{C}$ and 5 ), the LDG activity increases by $22.1 \%$ (Figure 5 ), the AP activity increases by $37.1 \%$ (Figure $4 \mathrm{D}, 4 \mathrm{~F}$ and 5 ). The G-6-PhDH activity decreases by $9.8 \%$ (Figure $4 \mathrm{G}, 4 \mathrm{I}$ and 5 ), the NADPhHDH activity decreases by $17.4 \%$. In addition, the sevenfold ethanol administration oppresses the activity of the mitochondria marker enzymes NADHDH by $11.6 \%$ (Figure 5) (it participates in transport of electrons) and SDH by $19.6 \%$ (Figure 5) (it indicates the Krebs cycle deceleration). Thus, the histochemical changes in histaminergic neurons may reflect both the disturbances of energy metabolism and metabolic adaptation of neurons to alcohol, taking into consideration the alcohol-induced hypoxia.

\section{Alcohol effects to a histaminergic neurons ultrastructure}

Injection of ethanol to animals produces a variety of ultrastructural changes in brain histaminergic neurons, some being common to single and repeated administration regimes and others being dependent on duration of exposure to alcohol.

Ethanol leads to hypertrophy and displacement of nucleoli towards the nuclear envelope, accumulation of electron-dense granular material (possibly ribosomal subunits) between the nucleolus and the nuclear envelope, and increases in the number of nuclear pores, as compared to control. Thus, histaminergic neurons following alcohol administration exhibit the structural signs of hyperactivity, the intensive functioning probably related to their adaptation to alcohol. $1 \mathrm{~h}$ after the sevenday ethanol administration some nuclei contain unusual vacuoles surrounded by single biological membrane (Figure 6B). Such vacuoles have been detected by us also $24 \mathrm{~h}$ after repeated administration of alcohol [19]. From our point of view, this may due to widening of the perinuclear space with large folding of the internal nuclear membrane. 

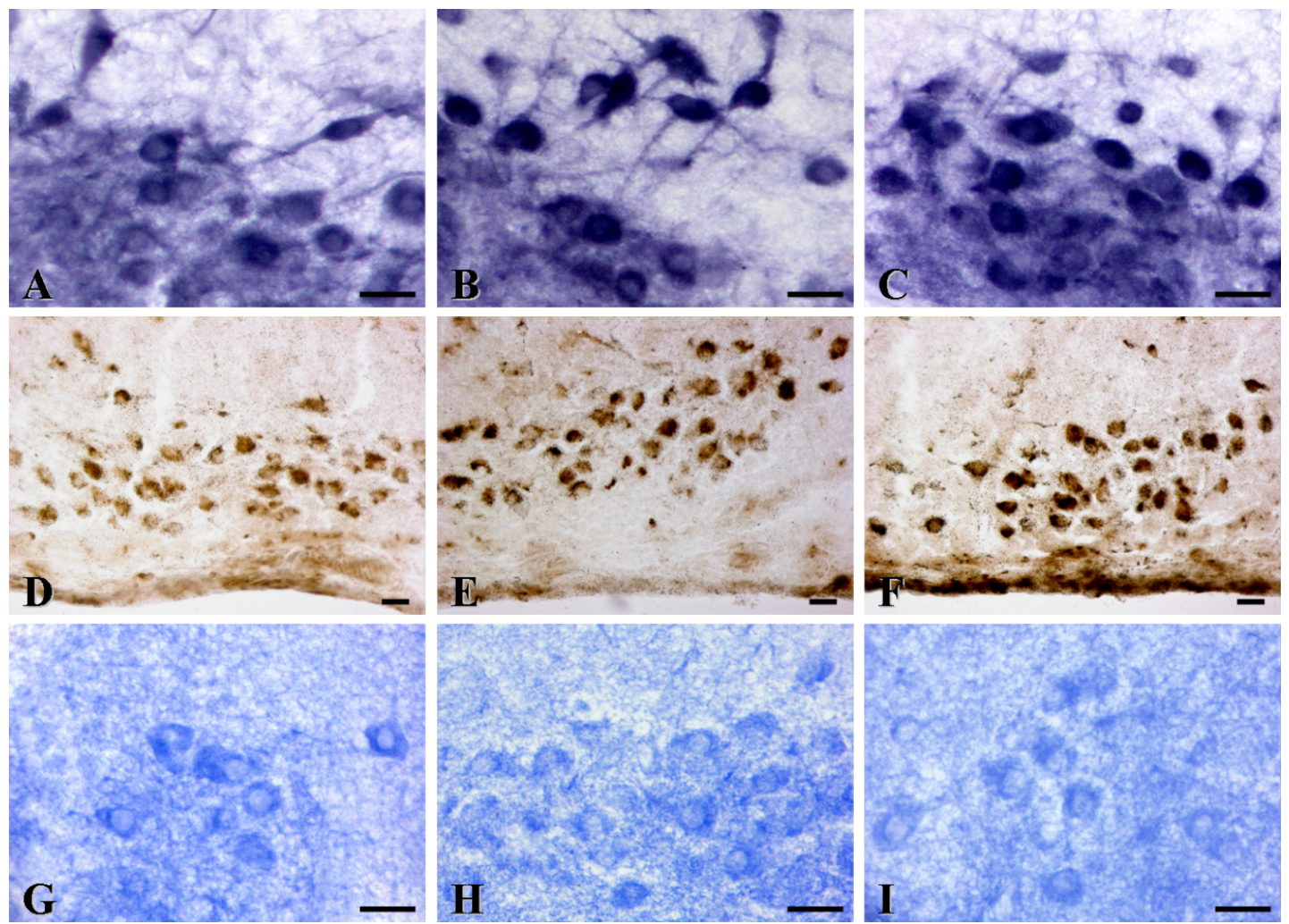

Figure 4. Enzyme activities in cytoplasm of histaminergic neurons of control rats (A, D, G), following single ethanol administration at a dose of $4 \mathrm{~g} / \mathrm{kg}, 1 \mathrm{~h}$ after the injection (B, E, H), and following sevenfold administration of ethanol at a dose of $4 \mathrm{~g} / \mathrm{kg} /$ day, $1 \mathrm{~h}$ after the last injection (C, F, I). A-C-Monoamine oxidase type B; D-F-Acid phosphatase; G-I-Glucose-6-phosphate dehydrogenase. Digital microphotographies. Magnifications: A-C, G-I-x400; D-F-x200. Scale bars: $15 \mu \mathrm{m}$

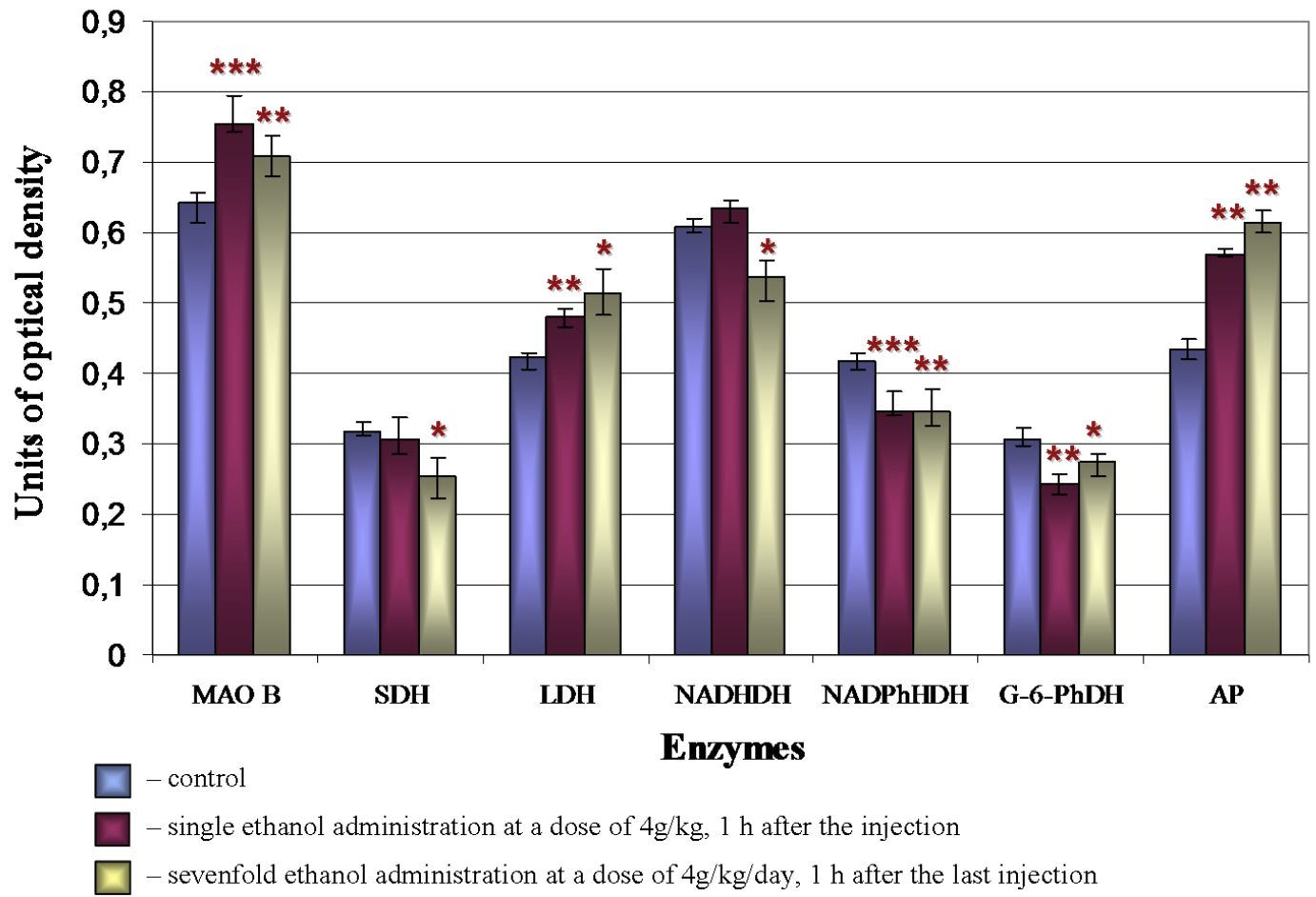

Figure 5. Changes of enzyme activities in cytoplasm of brain histaminergic neurons following ethanol administration. The enzymes studied (as described in the «Materials and methods» section) are represented on the horizontal axis, and the optical densities of chromogen obtained in the course of corresponding histochemical reactions are plotted on the vertical axis. Data are presented as median \pm interquartile range; ${ }^{*}$ - $p<0.05, *^{*}-\mathrm{p}<0.01,{ }^{* * *}$ - $\mathrm{p}<0.001$, as compared to controls (Mann-Whitney U-test) 

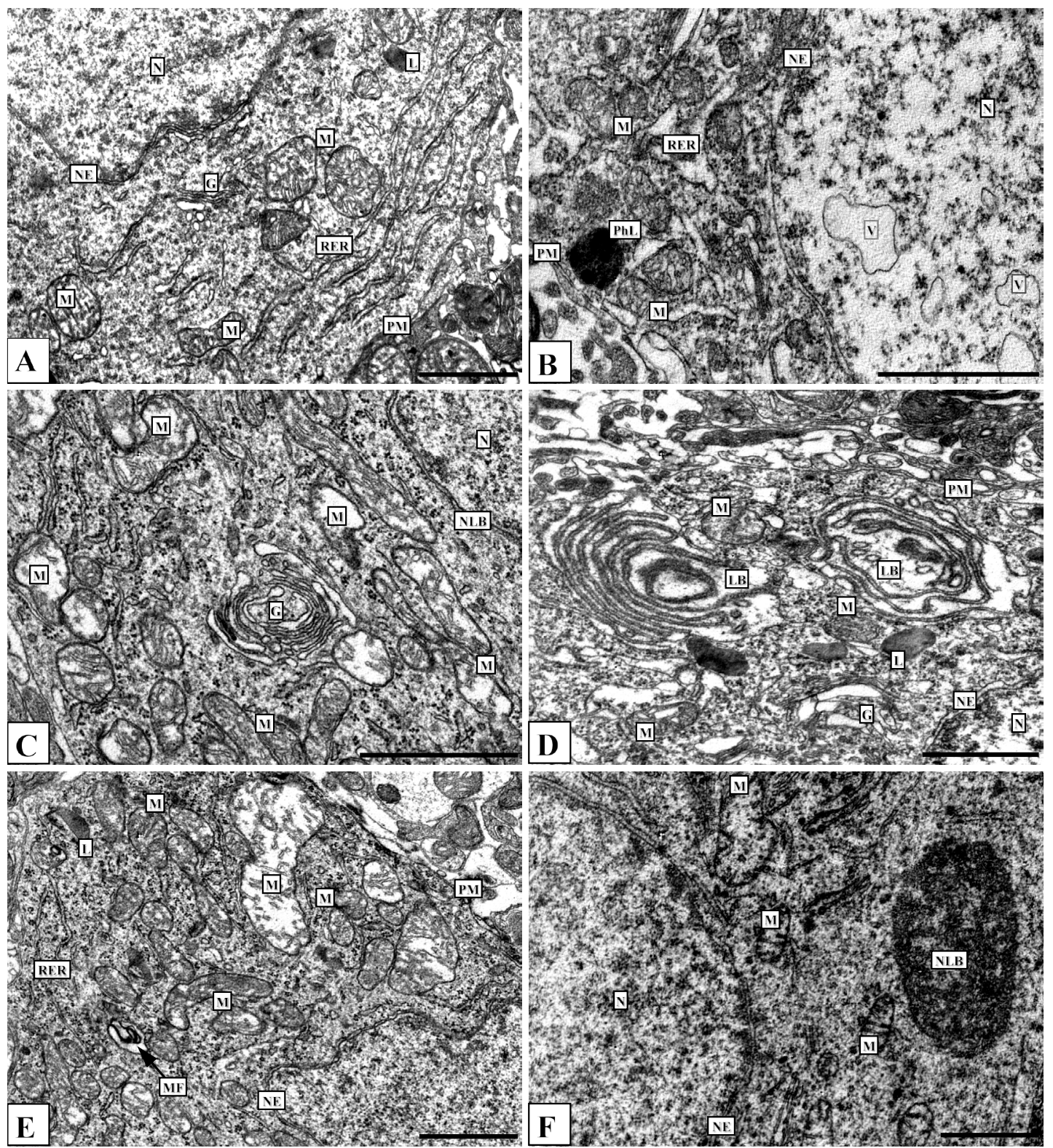

Figure 6. Histaminergic neurons of control rats (A), after single ethanol administration at a dose of $4 \mathrm{~g} / \mathrm{kg}(\mathrm{C}, \mathrm{E})$ and after seven-day ethanol administration at a dose of $4 \mathrm{~g} / \mathrm{kg} / \mathrm{day}$ (B, D, F). Designations: G-Golgi complex, L-lysosome, LB-lamellar body, M-mitochondria, MF-myelin-like figures, N-nucleus, NE-nuclear envelope, NLB-nucleolus-like body, Nu-nucleolus, PhL-phagolysosome, PM-plasma membrane, RER-rough endoplasmic reticulum, V-vacuole. Electron micrographs. Scale bars: $1 \mu \mathrm{m}$

Alcohol leads to widening of the endoplasmic reticulum channels (Figure 6B, 6D), as compared to controls (Figure 6A), a significant increase in the amount and size of lysosomes, closure of stacks of Golgi complex cisterns to form rings (Figure 6C), the appearance of myelin-like figures (Figure 6E), and mitochondrial hypertrophy and hyperplasia, accompanied by mitochondrial swelling and fragmentation and destruction of cristae (Figure 6C, 6E, 6F).

1 hour after the seven-day ethanol administration in some neurons the Golgi cisterns forms unusual cycles, lamellar bodies (Figure 6D). The cytoplasm of some histaminergic neurons shows nucleolus-like bodies-round or oval structures, of size about 1-2 $\mu \mathrm{m}$, which consist of osmeophilic granules aggregations with areas of lightening (Figure 6F).

Such structures were described earlier in neurons and glial cells of hypothalamus in other experimental conditions [20]. They contain the RNA-binding proteins and mRNA. They regulate the transcription and involved in mRNA degradation or storage, contribute to cell survival $[21,22]$. It can be suggested that repair processes (intracellular regeneration) in histaminergic neurons following ethanol administration occur in parallel with destruction processes. Such structures have been detected by us in cytoplasm of histaminergic neurons also under the influence of single low ethanol dose $(1 \mathrm{~g} / \mathrm{kg}, 1$ hour after administration) and following repeated administration of alcohol ( $4 \mathrm{~g} / \mathrm{kg} /$ day, for 7 days, 24 hours after the last injections) $[19,23]$. It demonstrates the huge potential capabilities of those neurons (Figure 7).

All structural and metabolic disturbances revealed in brain histaminergic neurons of rats after exposure to alcohol are nonspecific since they can be observed in other types of neurons under the other experimental conditions. They may reflect both alcohol-induced 


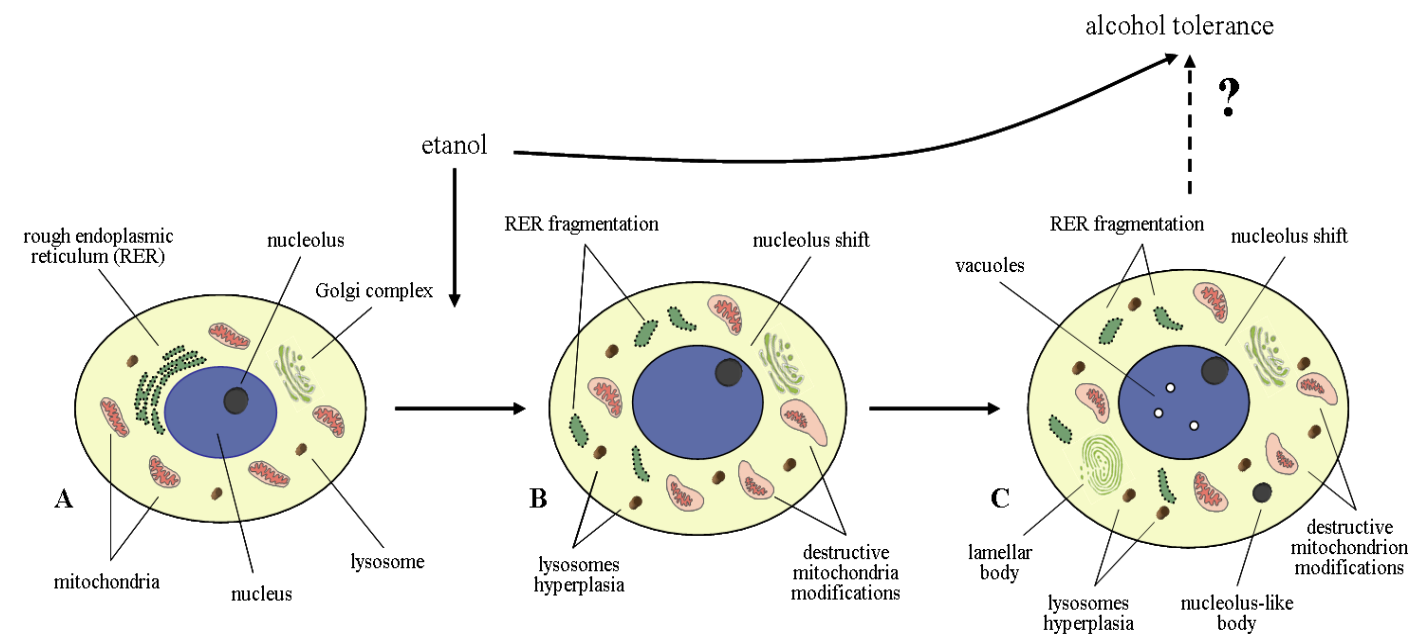

Figure 7. Histaminergic neurons of control rats (A), following single ethanol administration at a dose of $4 \mathrm{~g} / \mathrm{kg}, 1 \mathrm{~h}$ after the injection (B), and following sevenfold administration of ethanol at a dose of $4 \mathrm{~g} / \mathrm{kg} / \mathrm{day}, 1 \mathrm{~h}$ after the last injection (C)

morphofunctional disturbances and an adaptation of neurons to ethanol.

\section{Conclusion}

Acute and subacute alcohol intoxications lead to severe toxic and adaptive structural and metabolic changes of brain histaminergic neurons, some being common to single and repeated administration regimes and others being dependent on duration of exposure to alcohol (Figure 7).

\section{Funding}

Grodno State Medical University grant for reagents and animals.

\section{Conflict of interest statement}

None declared.

\section{References}

1. Haas HL, Sergeeva OA, Selbach O (2008) Histamine in the nervous system. Physio Rev 88: 1183-1241. [Crossref]

2. Wada H, Inagaki N, Yamatodani A, Watanabe T (1991) Is the histaminergic neuron system a regulatory center for whole-brain activity? Trends Neurosci 14: 415-418. [Crossref]

3. Haas H, Panula P (2003) The role of histamine and the tuberomamillary nucleus in the nervous system. Nat Rev Neurosci 4: 121-130. [Crossref]

4. Wada H, Inagaki N, Itowi N, Yamatodani A (1991) Histaminergic neuron system: morphological features and possible functions. Agents Actions Suppl 33: 11-27. [Crossref]

5. Brown RE, Stevens DR, Haas HL (2001) The physiology of brain histamine. Prog Neurobiol 63: 637-672. [Crossref]

6. Zimatkin SM, Kuznetsova VB, Strik ON (2006) Spatial organization and morphometric characteristics of histaminergic neurons in the rat brain. Neurosci Behav Physiol 36: 467-471. [Crossref]

7. Paxinos G, Watson C (2007) The rat brain in stereotaxic coordinates. ( $6^{\text {th }}$ edn). London: Academic Press, United Kingdom.

8. Yanai K, Tashiro M (2007) The physiological and pathophysiological roles of neuronal histamine: An insight from human positron emission tomography studies. Pharmacol Ther 113: 1-15. [Crossref]

9. Blandina P, Munari L, Provensi G, Passani MB (2012) Histamine neurons in the tuberomamillary nucleus: a whole center or distinct subpopulations? Front Syst Neurosci 6: 1-6. [Crossref]
10. Panula P, Nuutinen S (2013) The histaminergic network in the brain: basic organization and role in disease. Nat Rev Neurosci 14: 472-487. [Crossref]

11. Zimatkin SM, Anichtchik OV (1999) Alcohol-histamine interactions. Alcohol Alcohol 34: 141-147. [Crossref]

12. Panula P, Nuutinen S (2011) Histamine and $\mathrm{H} 3$ receptor in alcohol-related behaviors. $J$ Pharmacol Exp Ther 336: 9-16. [Crossref]

13. Zimatkin SM, Phedina KM (2017) Alcohol on histaminergic neurons of brain. In: RR Watson, Sh Zibadi eds. 2017. Addictive substances and neurological disease. Alcohol, tobacco, caffeine, and drugs of abuse in everyday lifestyles. Academic Press. Chapter 3: USA, pp: 23-27.

14. Zimatkin SM, Tsydik VF (1996) Histochemical method for investigating the activity of monoamine oxidase A and B in the brain. Neurosci Behav Physiol 26: 231-233. [Crossref]

15. Pearse AGE (1960) Histochemistry: theoretical and applied. ( $2^{\text {nd }}$ edn) London Churchill, United Kingdom.

16. Millonig G (1961) Advantages of a phosphate buffer for $\mathrm{O}_{5} \mathrm{O}_{4}$ solutions in fixation. $J$ Appl Phys 32: 1637-1643.

17. Watson ML (1958) Staining of tissue sections for electron microscopy with heavy metals. J Biophys Biochem Cytol 4: 727-730. [Crossref]

18. Reynolds ES (1963) The use of lead citrate at high $\mathrm{pH}$ as an electron-opaque stain in electron microscopy. J Cell Biol 17: 208-212. [Crossref]

19. Zimatkin SM, Phedina EM (2015) Seven-day ethanol administration influence on the rat brain histaminergic neurons. Alcohol 49: 589-595. [Crossref]

20. Kawabata I (1965) Electron microscopy of the rat hypothalamic neuro-secretory system. II. Nucleolus-like inclusion bodies in the cytoplasm of neurosecretory cells. Arch Histol Jpn 26: 101-113. [Crossref]

21. Decker CJ, Parker R (2012) P-Bodies and stress granules: possible roles in the control of translation and mRNA degradation. Cold Spring Harb Perspect Biol 4: a012286. [Crossref]

22. Thomas MG, Loschi M, Desbats MA, Boccaccio GL (2011) RNA granules: the good, the bad and the ugly. Cell Signal 23: 324-334. [Crossref]

23. Zimatkin SM, Fedina EM (2015) Ultrastructural changes in cerebral histaminergic neurons on exposure to alcohol. Neurosci Behav Physiol 45: 873-877.

Copyright: (C2017 Phedina KM. This is an open-access article distributed under the terms of the Creative Commons Attribution License, which permits unrestricted use, distribution, and reproduction in any medium, provided the original author and source are credited. 